\title{
Access and inference in categorization
}

\author{
LAWRENCE W. BARSALOU \\ Georgia Institute of Technology, Atlanta, Georgia
}

\begin{abstract}
This paper contains the remarks of the discussant in the symposium on social cognition held at the Annual Meeting of the Psychonomic Society in November 1989. Although much work in cognitive psychology and social cognition addresses categorization, these two areas of work currently exhibit little overlap. Whereas cognitive psychologists focus primarily on how people access categories, social cognitive psychologists focus primarily on how people draw inferences from categories. Cognitive psychologists have little to say about inference, often seeming to view categorization as an end in itself. Social cognitive psychologists typically ignore how people access categories for individuals, behaviors, and situations. Because access and inference are both intrinsic parts of categorization, complete theories of categorization must address both in a balanced and integrated manner.
\end{abstract}

The topic of categorization is currently receiving much attention in the fields of cognitive psychology and social cognition. In cognitive psychology, category learning and the classification process have received much study (e.g., McClelland, Rumelhart, \& the PDP Research Group, 1986; Medin \& Smith, 1984; Mervis \& Rosch, 1981; Oden, 1987; Rumelhart, McClelland, \& the PDP Research Group, 1986; Smith \& Medin, 1981). As a result, theorists have proposed various models of learning and classification, including prototype models, exemplar models, and-most recently-connectionist models. In social cognition, the social categories that underlie person perception have received much study (e.g., Greenwald, 1990; Hastie, Schroeder, \& Weber, 1990; Higgins, 1990; and Read, 1990, in this issue; see also Fiske \& Taylor, 1984; Sherman, Judd, \& Park, 1989). Given the amount of work on categorization in cognitive psychology and social cognition, what do these two areas have to say to each other about this important topic? One might think a lot. But I will argue that there is surprisingly little overlap at present.

What do I mean when I say that there is little overlap between cognitive psychology and social cognition in the study of categorization? Consider the general account of categorization in Figure 1. According to this view, categorization begins with the extraction of featural information from the entity that is being categorized. This information is then projected to memory, accessing prototypes, exemplars, a connectionist net, what have you. As a result, probable categories become active, and a decision rule selects the one best justified by the current featural evidence. Once a category has been assigned to the entity, inferences about the entity may be produced. These inferences may concern the origin of the entity or

Work on this paper was supported by National Science Foundation Grant IRI-8609187 and Army Research Institute Contract MD A90386-C-0172. Address correspondence to Lawrence W. Barsalou, School of Psychology, Georgia Institute of Technology, Atlanta, GA 30332.

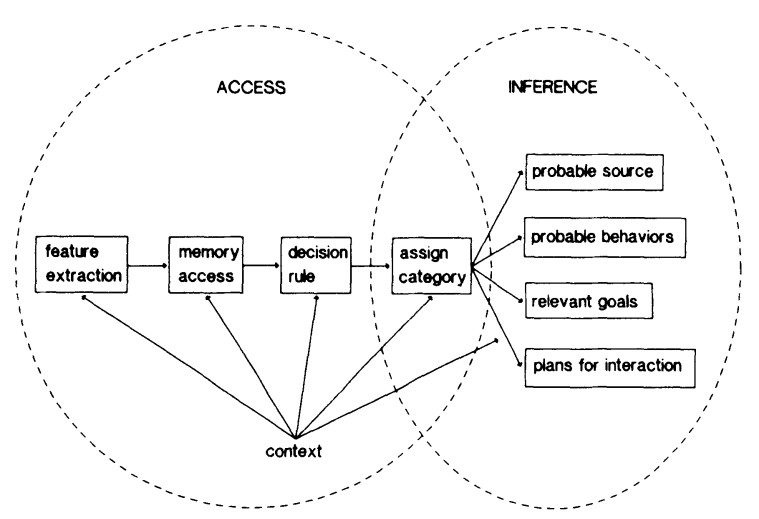

Figure 1. Access and inference phases of categorization.

its features, behaviors of the entity likely to be observed, the relevance of the entity to the perceiver's goals, or plans for interacting with the entity to achieve these goals. At all points, current context may exert top-down effects on processing (e.g., McClelland \& Rumelhart, 1981; Rumelhart \& McClelland, 1982). Figure 1 depicts an overview of categorization that I suspect would receive general endorsement from many researchers.

Note that there are two general phases to the overall categorization process in Figure 1. In the first phase, a category is accessed and assigned to the stimulus. I will refer to the issues surrounding this phase of categorization as the access problem. In the second phase, knowledge associated with the category provides inferences about the categorized entity. I will refer to the issues surrounding this phase of categorization as the inference problem. Although the initial goal in categorization is to figure out what something is-the access problem-the ultimate goals are often to figure out how the categorized entity originated, what it is likely to do, what implications it has for our goals, and what plans we should implement to interact with it. In other words, we don't just categorize something to know its category. Instead, we 
categorize something to access inferential knowledge that is relevant to understanding and interacting with it.

My general impression is that most-but certainly not all-of the cognitive psychologists working on categorization are addressing the access problem. Prototype, exemplar, and connectionist models typically address how we access the correct category in memory. Interestingly, these researchers have worried relatively little about the inference problem. If one wanted to be ungenerous, one could say that cognitive psychologists assume that accessing a category is an end in itself and that the ultimate goal is simply categorization. If one wants to be generous, and perhaps realistic, one could say that accounting for access is a significant problem of great importance and complexity, with focusing on it to the exclusion of inference being a reasonable scientific strategy.

In contrast, most social cognitive psychologists working on categorization ignore the access problem. Instead, they typically assume that a category is somehow given and that the key problem concerns how one draws inferences about the categorized entity, which is typically a person, behavior, or situation. Indeed, categorical inference is another significant problem of great importance and complexity. As we can see in the preceding collection of papers from the present symposium, many interesting phenomena occur during the inference phase of categorization.

Consider the work of Anthony Greenwald (1990). His work demonstrates one of the simplest and perhaps most fundamental inferences following categorization: affective evaluation. Once we access a category, information associated with the category may produce a positive or negative evaluation of the categorized entity. These affective evaluations may often reflect the entity's inferred potential for fulfilling or frustrating some goal of the perceiver. As Greenwald's work further illustrates, these affective inferences can become fairly complex. When a person categorizes something as an essay, for example, affective responses associated with essays in general may become available. But our affective response may be further controlled by other categories associated with the essay, such as categorizations of the individual who wrote it. As Greenwald shows, categorization of the author's attractiveness contributes to the perceiver's affective response toward the essay. Ultimately, these affective inferences may control behavior, thus determining-perhaps unconsciously - the grade the essay receives.

Tory Higgins's (1990) work demonstrates affective inferences that are perhaps still more complex. If a sad person categorizes someone else as cheerful, the sad person may note the discrepancy, compare this discrepancy to an ideal self, and infer that the discrepancy signifies a selflimitation. This final inference may in turn produce mood and behavioral changes, similar to the process described in Greenwald's work. An initial categorization can produce a long chain of inferences that eventually produces significant effects in behavior.
Stephen Read's work (Read, Miller, \& Jones, 1990) demonstrates another important type of inference: inferences about the origin of a categorized entity. For example, if a perceiver observes someone exhibiting a particular behavior, the perceiver may try to determine the cause of that behavior. As much research has shown, perceivers often attribute causes of behaviors to underlying personality traits that may not exist, rather than to social situations (see, e.g., Mischel, 1968, 1983; Nisbett \& Ross, 1980). Read et al. (1990) suggest that inferences about an actor's traits may ultimately be inferences about the actor's goals.

Finally, Reid Hastie's work (Hastie, Schroeder, \& Weber, 1990) demonstrates what might be called resolution inferences. When we categorize an entity simultaneously into two categories, the categories may produce incompatible inferences. As a result, we need to perform additional processing - perhaps using causal scenarios-to resolve the conflict. The outcome may be the production of newly inferred knowledge that applies to the conjunction of the two categories but not to either individually.

In all four of these social cognition projects, category access is assumed to be a given. The problem addressed by a particular investigator always begins with the presence of a category or multiple categories. The critical analysis then addresses what happens thereafter during the inference process. There are no accounts of how people, behaviors, or situations are categorized initially. Clearly, this omission is understandable, given the strategy of divide and conquer. Inference is a sufficiently important and complex problem to receive isolated attention.

In summary, then, my impression is that cognitive psychologists and social cognitive psychologists are both working on categorization but focusing on different phases of this process. Clearly, there are some social cognitive psychologists who have worked on category access, such as Newtson (1976) and McArthur (1982). Clearly, there are some cognitive psychologists who have worked on categorical inference, such as Rips (1975), Osherson, Smith, Wilkie, Lopez, and Shafir (in press), Medin and Shoben (1988), and Murphy (1988). But in general, cognitive psychologists emphasize access, and social cognitive psychologists emphasize inference.

These emphases can be seen in the topics that have received study from both cognitive psychologists and social cognitive psychologists. For example, consider the work on intuitive theories. Cognitive psychologists are generally interested in how intuitive theories constrain the features used in access (Murphy \& Medin, 1985). In contrast, social cognitive psychologists are generally interested in how intuitive theories constrain and guide the inference process during impression formation (e.g., Asch \& Zukier, 1984). Similarly, consider work on conceptual combination. Cognitive psychologists tend to be interested in how we access and identify combined concepts (e.g., Osherson \& Smith, 1981, 1982; Hampton, 1987, 
1988). In contrast, social cognitive psychologists tend to be interested in how we draw inferences about combined concepts (e.g., Hastie et al., 1990; Kunda, Miller, \& Steidley, in press).

So again, cognitive psychologists generally emphasize the access problem, whereas social cognitive psychologists generally emphasize the inference problem. This arrangement seems fine, as long as each issue can be addressed without the benefit of insights from the other, which may be a dubious proposition.

If we were to attempt a more complete integration of work on categorization that incorporates both access and inference, what new issues might be raised? Consider how cognitive psychologists could extend their work to inference. First, we could study categories for which inferences are important. Interestingly, most of the artificial categories studied by cognitive psychologists don't yield interesting inferences about source, behavior, goals, or plans (e.g., dot patterns, geometric shapes, schematic faces). Instead, these categories only lend themselves to questions of access, with access as an end in itself. But if we are to understand the general role that categories play in cognition, we need to study categories whose sources, behaviors, goals, and plans are meaningful. Second, cognitive psychologists could explore the types of inferences that people make about natural categories. What mechanisms underlie such inferences? What conditions cause these inferences to be produced? To what extent are inferences about social and nonsocial entities similar? Third, to what extent do inferences shape the categories we choose to construct in the first place? Do categories simply reflect the informational structure of the environment? Or do we construct categories to support inferences that are relevant to our goals?

Consider issues that might be raised for social cognition from a more integrated approach. How do we recognize different types of people? When we perceive someone for the first time, what classifications do we perform? What factors influence these categorizations, including perceptual, contextual, and intentional factors? I doubt that the basic level identified in Cantor and Mischel (1979) constitutes the initial classifications of individuals (e.g., arts patron). Instead, more perceptually based categories, such as black woman and white boy, may be basic during access, although the basic categories of Cantor and Mischel may be preferred during inference (Barsalou \& Billman, 1989, pp. 176-178). Similar issues exist for categorizing other social objects. How do we categorize behaviors? How do we categorize situations?

Social categorizations don't always occur while one is perceiving the categorized entity. We often categorize people through various forms of hearsay about them, by viewing their environment, by encountering their work, or through some other effect of their behavior. How do we perform these categorizations? How do they differ from those based on direct experience? Much remains to be learned about both direct and indirect forms of social categorization.

Both access and inference are essential aspects of the categorization process, and it is good to see each one receiving so much attention. But perhaps it would be more optimal if treatment of access and inference were integrated, both for social and nonsocial categories.

\section{REFERENCES}

Asch, S. E., \& ZUKIER, H. (1984). Thinking about persons. Journal of Personality \& Social Psychology, 46, 1230-1240.

Barsalou, L. W., \& Billman, D. (1989). Systematicity and semantic ambiguity. In D. Gorfein (Ed.), Resolving semantic ambiguity (pp. 146-203). New York: Springer-Verlag.

Cantor, N., \& Mischel W. (1979). Prototypes in person perception. In L. Berkowitz (Ed.), Advances in experimental social psychology (Vol. 12, pp. 3-52). San Diego: Academic Press.

FISKe, S. T., \& TAYLOR, S. E. (1984). Social cognition. Reading, MA: Addison-Wesley.

Greenwald, A. G. (1990). What cognitive representations underlie social attitudes? Bulletin of the Psychonomic Society, 28, 254-260.

Hampton, J. A. (1988). Overextension of conjunctive concepts: Evidence for a unitary model of concept typicality and class inclusion. Journal of Experimental Psychology: Learning, Memory, \& Cognition, 14, 12-32.

Hastie, R., Schroeder, C., \& Weber, R. (1990). Creating complex social conjunction categories from simple categories. Bulletin of the Psychonomic Society, 28, 242-247.

HiggiNs, E. T. (1990). Self-state representations: Patterns of interconnected beliefs with specific holistic meanings and importance. Bulletin of the Psychonomic Society, 28, 248-253.

Kunda, Z., Miller, D. T., \& STEIDley, T. (in press). Combining social concepts: The role of causal reasoning. Cognitive Science.

MCARThUR, L. Z. (1982). Judging a book by its cover: A cognitive analysis of the relationship between physical appearance and stereotyping. In A. H. Hastorf \& A. Isen (Eds.), Cognitive social psychology (pp. 149-211). New York: Elsevier/North-Holland.

McClelland, J. L., \& RumelhaRT, D. E. (1981). An interactive activation model of context effects in letter perception: Part I. An account of basic findings. Psychological Review, 88, 375-407.

McClelland, J. L., Rumelhart, D. E., \& the PDP Research GrouP. (1986). Parallel distributed processing: Explorations in the microstructure of cognition: Vol. 2. Psychological and biological models. Cambridge, MA: MIT Press.

Medin, D. L., \& ShOBEn, E. J. (1988). Context and structure in conceptual combination. Cognitive Psychology, 20, 158-190.

Medin, D. L., Smith, E. E. (1984). Concepts and concept formation. Annual Review of Psychology, 35, 113-138.

Mervis, C. B., \& Rosch, E. (1981). Categorization of natural objects. Annual Review of Psychology, 32, 89-115.

Mischel, W. (1968). Personality and assessment. New York: Wiley.

Mischel, W. (1983). Alternatives in the pursuit of the predictability and consistency of persons: Stable data that yield unstable interpretations. Journal of Personality, 51, 578-604.

MurPhy, G. L. (1988). Comprehending complex concepts. Cognitive Science, 12, 529-562.

MurPhy, G. L., \& MEDIN, D. L. (1985). The role of theories in conceptual coherence. Psychological Review, 92, 289-316.

NewTSON, D. (1976). The perception of ongoing behavior. In J. H. Harvey, W. J. Ickes, \& R. F. Kidd (Eds.), New directions in attribution research (Vol. 1, pp. 223-247). Hillsdale, NJ: Erlbaum.

NisBett, R. E., Ross, L. (1980). Human inference: Strategies and shortcomings of social judgment. Englewood Cliffs, NJ: Prentice-Hall.

ODEN, G. C. (1987). Concept, knowledge, and thought. Annual Review of Psychology, 38, 203-227. 
OSherson, D. N., \& SMITH, E. E. (1981). On the adequacy of prototype theory as a theory of concepts. Cognition, 9, 35-58.

Osherson, D. N., \& SMith, E. E. (1982). Gradedness and conceptual combination. Cognition, 12, 299-318.

Osherson, D. N., Smith, E. E., Wilkie, O., Lopez, A., \& Shafir, E. (in press). Category based induction. Psychological Review.

Read, S. J., Miller, L. C., \& Jones, D. K. (1990). Goals in the conceptual coherence of social categories. Bulletin of the Psychonomic Society, 28, 261-267.

RIPs, L. (1975). Inductive judgments about natural categories. Journal of Verbal Learning \& Verbal Behavior, 14, 665-681.
Rumelhart, D. E., \& McClelland, J. L. (1982). An interactive model of context effects in letter perception: Part 2 . The contextual enhancement effect and some tests and extensions of the model. Psychological Review, 89, 60-94.

Rumelhart, D. E., McClelland, J. L., \& the PDP Research Group. (1986). Parallel distributed processing: Explorations in the microstructure of cognition: Vol. 1. Foundations. Cambridge, MA: MIT Press. Sherman, S. J., Judd, C. M., \& Park, B. (1989). Social cognition. Annual Review of Psychology, 40, 281-326.

Smith, E. E., \& Medin, D. L. (1981). Categories and concepts. Cambridge, MA: Harvard University Press.

\title{
Notices and Announcements
}

\author{
Seventh Annual Conference \\ British Psychological Society - Cognitive Psychology Section \\ Leicester, England \\ September 7-9, 1990
}

The Seventh Annual Conference of the BPS Cognitive Psychology Section will be held at Beaumont Halls of Residence, Leicester, from Friday, September 7, to Sunday, September 9, 1990.

In addition to papers and symposia on a wide variety of topics in cognitive psychology, the conference program will include invited presentations by four guest speakers: Max Coltheart (Macquarie University, Australia), Dianne Berry (University of Oxford), Dorothy Bishop (University of Manchester), and Graham Davies (University of Leicester).

Each proposal should contain an abstract of $130-150$ words. The deadline for submissions is May 2, 1990. Registration forms and further details may be obtained from John R. Beech, Psychology Department, University of Leicester, Leicester LE1 7RH, England. 